\title{
Prevalence of dental caries and caries- related risk factors in premature and term children
}

\section{Vanessa Resende Nogueira Cruvinel(a) \\ Danuze Batista Lamas Gravina ${ }^{(b)}$ Tatiana Degani Paes Leme Azevedo(a) \\ Ana Cristina Barreto Bezerra ${ }^{(c)}$ Orlando Ayrton de Toledo(c)}

(a) PhD, School of Dentistry, Catholic University of Brasília, Brasília, DF, Brazil.

(b) Master, University of Brasília, Brasília, DF, Brazil.

(c) PhD, School of Dentistry, University of Brasília, Brasília, DF, Brazil.
Corresponding author:

Vanessa Resende Nogueira Cruvinel

Colônia Agrícola Samambaia

Rua 01, Ch. 99, Casa "C" - Taguatinga

CEP: $72110-600$

Brasília - DF - Brazil

E-mail:vanessarcruvinel@gmail.com

Received for publication on Apr 22, 2010 Accepted for publication on Jul 09, 2010

\begin{abstract}
This study evaluated the prevalence of enamel defects and dental caries and their risk factors on primary and permanent dentitions of prematurely-born children and term children. Eighty children were examined, 40 born prematurely (G1) and 40 born term (G2), in the age group between 5 and 10 years. The demographic variables, medical history and oral health behaviors were recorded on a questionnaire. The teeth were examined for presence of deficiencies of the enamel and caries that were registered. The caries were registered, focusing on the indices dmft (decayed, missing, and filled primary teeth) and DMFT (decayed, missing, and filled permanent teeth). The results showed that $75 \%$ of the total sample had enamel defects. The logistic regression model showed that other risk factors such as per capita family income, educational level, dietary and hygiene habits, fluoride exposure, trauma, and diseases had no correlation with enamel defects and caries. A smaller value of total DMFT (0.95) was found in the group of premature children in comparison to the term children $(2.07) \mathrm{p}=0.0164$. There was no difference concerning the permanent dentition between the two groups $(\mathrm{p}=0.9926)$. One concludes that prematurity can't be a predisposing factor for the presence of dental caries.
\end{abstract}

Descriptors: Premature birth; Dental enamel; Dental caries; Dentition, mixed.

\section{Introduction}

Advances in medicine, combined with the monitoring and technologies used in intensive care units, have provided favorable prognosis with decreased mortality and incidence of damage to premature newborns.

The birth of low weight, premature infants ( $<37$ weeks) is a costly social, family and public health problem. ${ }^{1}$ Preventive and health promoting measures are necessary to improve the quality of life of these children. Thus, knowledge of the risk factors to which these children are subjected is of paramount importance in adopting such measures.

Low gestational age and low birth weight are among the key factors in determining the incidence of neonatal complications. Among the most prevalent oral diseases in these children are dental enamel opacities and hypoplasias. ${ }^{2,3}$ The source of these defects is related to disturbances during amelogenesis. ${ }^{4}$ Hypoplastic areas are reported as susceptible to dental caries, ${ }^{5,6}$ as ultrastructural analysis showed a more porous, less 
mineralized enamel with irregular surfaces. This allows the accumulation of bacteria and promotes the colonization of Streptococcus mutans, resulting in carious lesions. ${ }^{78}$ Considering the multifactorial etiology of caries, one should be aware of the risk factors associated with this disease so as to decrease its prevalence and prevent these children's pain and suffering. ${ }^{9,10}$

By knowing that children born prematurely may have changes in their dental structures, and that these may be related to the development of caries, concern should be focused on their risk groups. In light of this evidence, this study aimed to evaluate the relationship between enamel defects and other risk factors for dental caries with the prevalence of dental caries in the dentitions of children born prematurely, as compared to those born term.

\section{Material and Methods}

This sample consisted of 80 children of both genders, born between 2000 and 2004 at the Hospital Regional da Asa Sul (HRAS) in Brasília, Brazil, who had participated in a previous study, ${ }^{2}$ and are currently aged between 5 and 10 years. Forty of the children were preterm, and 40 were term.

This study was approved by the Research Ethics Committee of the Catholic University of Brasília (UCB) under number 161/2008.

The children were recruited to go to the university to participate in this study. A questionnaire was used to obtain data such as name, age, gender, family income, residence address, parents' occupation, diet and exposure to fluoride. ${ }^{2}$ The presence of enamel defects, socioeconomic factors, maternal education level, exposure to fluoridated water, cariogenic diet and oral hygiene habits were assessed as possible risk factors associated with the occurrence of dental caries. ${ }^{11}$

Regarding the categorization of family socioeconomic status, the standard variables defined by the National Household Sample Survey (PNAD) were applied. ${ }^{12}$ For the calculation of income, the minimum wage in force in the months covered by the survey ( $\mathrm{R} \$ 465.00)$ was considered. These variables were classified into 2 groups: one $\leq 1 / 2$ minimum wage (G1), and one above $1 / 2$ minimum wage
(G2). ${ }^{13}$ To analyze the diet, a survey of the parents' memory of food intake over the last 24 hours ${ }^{14}$ was carried out. The intake of more than 5 cariogenic foods within a one day period was labeled as a cariogenic diet. The population was divided into 2 categories: five or fewer sweet snacks per day, and more than five sweet snacks per day. ${ }^{15}$

Exposure to fluoride was considered as either systemic or topical. The former refers to children living in areas with fluoridated water supply, and the latter to those who made regular use of fluoridated toothpaste. ${ }^{16}$

Hygiene habits were assessed according to the amount of daily tooth brushing. Two daily tooth brushings indicated a lower risk factor for caries, and below this number indicated a probable risk factor. ${ }^{16}$

Subsequently, the children were examined under artificial light in a dental chair. Mouth mirror and sickle probe were used in the oral examination. Before the examination, each tooth was cleaned with gauze in order to remove gross plaque or food deposits, and to dry the surfaces. The tooth surfaces were examined for the presence of enamel structural defects and dental caries, using the Decayed, Missing or Filled Teeth Index (dmft) for deciduous teeth, and (DMFT) for permanent teeth. A tooth was considered present when any part of its clinical crown was exposed in the oral cavity. ${ }^{14,17,18}$

White spot carious lesions (active and inactive) were recorded for the purpose of differential enamel opacity diagnosis. ${ }^{14}$ These were not factored into the DMFT.

The same examiner, validated in a previous pilot study, performed the evaluations. To establish the degree of intra-examiner concordance the Kappa index was used in $10 \%$ of the sample, in agreement with World Health Organization (WHO) guidelines. Subjects were reexamined one week after the initial examination (Kappa $=0.90$ for opacities, hypoplasia and white spots; and 0.96 for cavitated and/or restored carious lesions).

For the diagnosis of enamel defects, codes were used according to the criteria of the Developmental Defects of Enamel Index (DDE Index). ${ }^{4}$ Enamel hypoplasia was defined as a break in the continuity 
of the enamel, in the form of pits, grooves, or missing enamel. Enamel opacity was defined as a change in the translucency of enamel, without a break in the enamel continuity. The extent, type and color of each defect were recorded. Subsequently, these variables were classified into 4 groups: demarcated opacity, diffuse opacity, hypoplasia and other defects.

\section{Data analysis}

To compare the scores obtained for opacity, hypoplasia and caries, the nonparametric Mann-Whitney test was performed at the $5 \%$ significance level.

To study the possible risk factors associated with the occurrence of caries, a multivariate logistic regression was performed. The occurrence of caries was the dependent variable. Type of birth was considered a risk factor, and the following variables were seen as potential confounders: tooth brushing, fluoridated drinking water, maternal education level, diet, enamel opacity, hypoplasia and per capita income.

\section{Results}

The children's mean age was 6.3 years for the premature group, and 7.6 years for the term group. Of the total sample, 21 children had deciduous dentition and 59 had mixed dentition, with an average of 14 deciduous and 8 permanent teeth present in the oral cavity.

The average weight of the premature infants was $1,255 \mathrm{~g}$, and of the term infants was 3,398 g. Thirty six of the 40 premature infants were born with very low birth weight, leading us to classify them within the same risk group.

Opacity was found in $64 \%$ of the children. Hypoplasia was detected in $22.5 \%$ of the sample. When the children were divided into premature (G1) and term (G2) groups, opacity was detected in $65 \%$ of G1 and $62.5 \%$ of G2. The difference was not statistically significant $(\mathrm{p}=0.8161)$. Hypoplasia was found in $37.5 \%$ and $7.5 \%$ of the children in G1 and G2, respectively. This difference was statistically significant $(\mathrm{p}=0.0013)$.

Six hundred and eleven teeth were assessed in G1: 43 (7\%) had demarcated opacity, $0(0 \%)$ had diffuse opacity and $42(6 \%)$ had hypoplasia. Five hundred and five teeth were examined in group G2: 19 (3.76\%) showed demarcated opacity, 0 (0\%) showed diffuse opacity and $4(0.8 \%)$ showed hypoplasia. A statistically significant difference was found between the groups in terms of demarcated opacity $(\mathrm{p}=0.0174)$ and hypoplasia $(\mathrm{p}<0.001)$.

The means of the total DMFT indices for children in the premature (G1) and term (G2) groups were 0.95 and 2.07 , respectively. Children in the term group had higher mean dental caries scores than children in the premature group $(\mathrm{p}=0.0164)$.

Of all compromised teeth found in both groups, $51.67 \%$ were decayed, $40 \%$ were filled and $8.33 \%$ were missing, as shown in Graph 1.

As regards DMFT, the children in group 1 and group 2 showed, respectively, $72.97 \%$ and $42.17 \%$ decayed teeth $(\mathrm{p}=0.002), 0.0 \%$ and $12.05 \%$ missing teeth $(p=0.064)$ and $27.03 \%$ and $45.78 \%$ filled teeth $(\mathrm{p}=0.053)$, as shown in Graph 2. The percentage of caries-free children in the two groups was $57.5 \%(\mathrm{G} 1)$ and $35 \%(\mathrm{G} 2)(\mathrm{p}=0.0436)$.

The means of dmft of children in the premature (G1) and term (G2) groups were 0.78 and 1.88, respectively. Children in the term group had higher mean scores of dental caries in primary teeth than the children in the premature group $(\mathrm{p}=0.0251)$. The results for the mean number of missing teeth and filled teeth in both groups are shown in Graph 3.

The mean DMFT index of children in the premature (G1) and term (G2) groups was found to

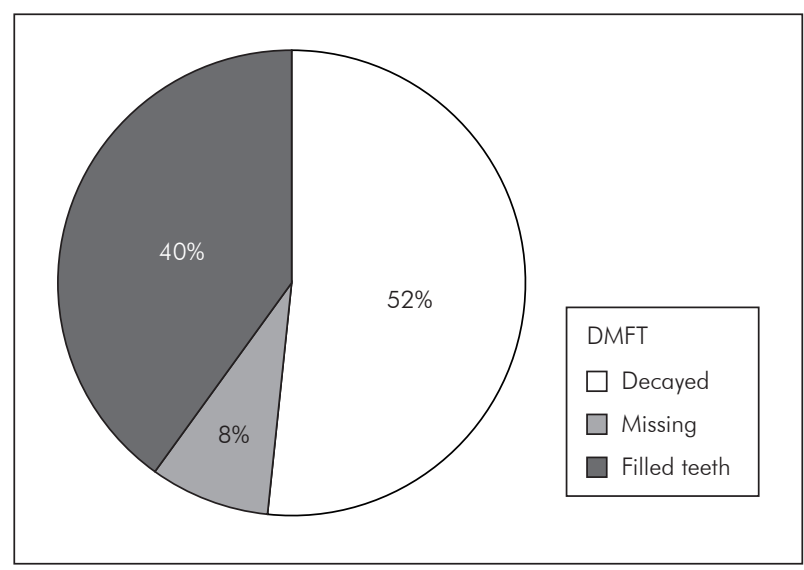

Graph 1 - DMFT Index (decayed, missing and filled teeth) for the total sample. 


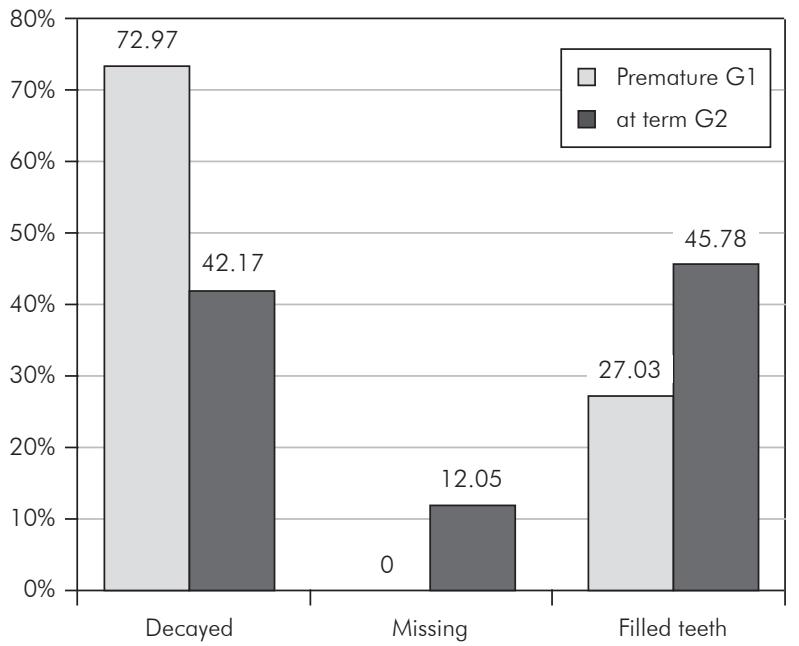

Graph 2 - Total DMFT Index (decayed, missing and filled teeth) for groups 1 and 2 .

be the same $(0.18)$ for both groups $(\mathrm{p}=0.9926)$ in permanent teeth. The results for the average number of permanent decayed, missing and filled teeth for both groups are shown in Graph 4.

After analyzing the variables that were considered as probable risk factors for the occurrence of caries, we obtained the results shown in Table 1.

By relating the type of birth - as the leading variable - to the independent variables for the occurrence of dental caries through logistic regression, we reached the following preliminary bivariate analysis results: per capita income $(\mathrm{p}=0.39)$, level of parental education $(\mathrm{p}=0.52)$, exposure to fluoride $(\mathrm{p}=0.68)$, amount of tooth brushing $(\mathrm{p}=0.26)$, diet $(p=0.09)$, presence of opacity $(p=0.63)$ and hypoplasia $(\mathrm{p}=0.70)$. Diet was the only independent variable influencing the dependent variable $(\mathrm{p}=0.09)$.

Based on the bivariate analysis results, diet was the only variable included - along with the type of birth variable - in the multivariate model, at the $5 \%$ significance level. By controlling the effects of the diet variable, type of birth was not found to be a risk factor for the occurrence of dental caries $(\mathrm{p}=0.1060)$ with an odds ratio of $0.46(0.18$ to 1.18).

\section{Discussion}

Approximately $54 \%$ of the sample had at least 1

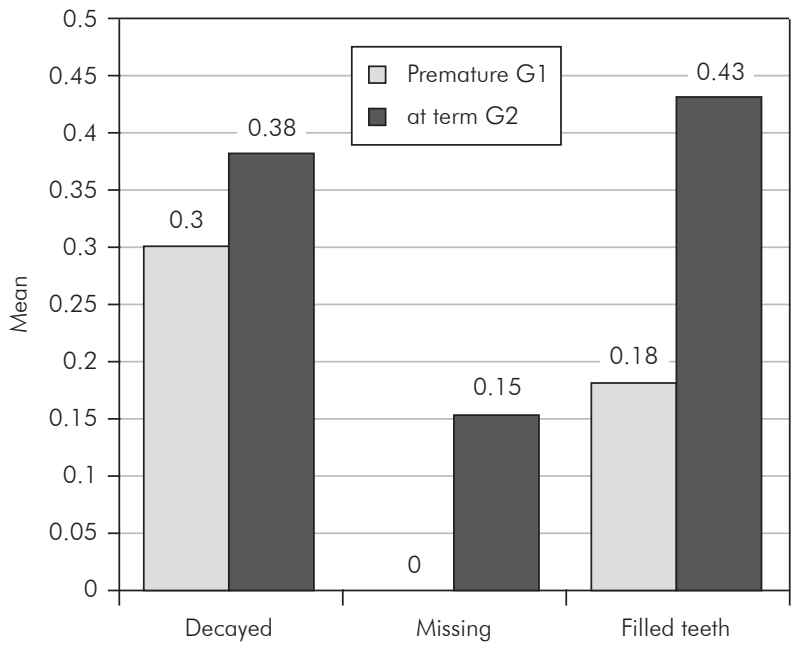

Graph 3 - Mean DMFT index (decayed, missing, or filled teeth) of groups 1 and 2 .

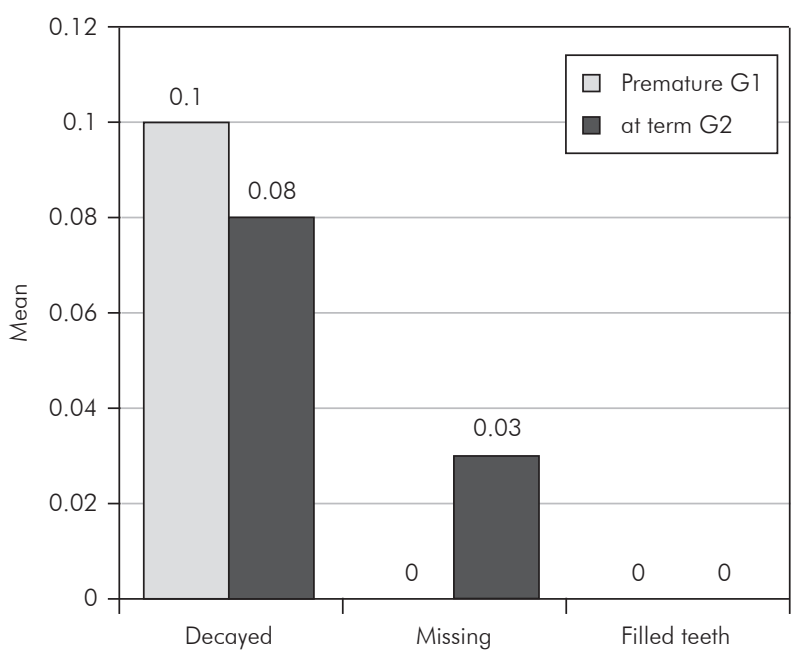

Graph 4 - Total DMFT Index for Permanent teeth (decayed, missing and filled teeth) in groups 1 and 2 .

decayed, missing or filled tooth, which reflects the socioeconomic status of this population. Children in the term group had higher mean dental caries scores than children in the premature group $(\mathrm{p}=0.0164)$. Opposite results were found by Fadavi et al., ${ }^{19} \mathrm{Maa}-$ touk et al. ${ }^{20}$ and Lai et al. ${ }^{21}$

Type of birth was a risk factor for the occurrence of hypoplasia $(p=0.0034)$ in primary dentition, in which premature children were 7.4 times more likely to present with this defect than term children $(\mathrm{RI}=95 \%)$. These findings agree with those of Massoni et al., ${ }^{13}$ who found a significant correlation 
Table 1 - Caries risk factors in groups $\mathrm{G} 1$ and $\mathrm{G} 2$.

\begin{tabular}{l|r|r|r|r|c}
\hline \multirow{2}{*}{\multicolumn{1}{c|}{ Risk Variable }} & \multicolumn{2}{|c|}{ Premature } & \multicolumn{2}{c|}{ Term } & \multirow{2}{*}{ P } \\
\cline { 2 - 5 } & $\mathrm{N}$ & \multicolumn{1}{c}{$\%$} & $\mathrm{~N}$ & $\%$ & \\
\hline Schooling $<8$ years & 7 & 17.50 & 8 & 21.05 & 0.6907 \\
\hline $\begin{array}{l}\text { Per capita income of less than } 0.5 \\
\text { minimum wage }\end{array}$ & 16 & 40.00 & 21 & 52.00 & 0.3576 \\
\hline Tooth brushing $<2$ times a day & 1 & 2.50 & 3 & 7.50 & 0.2622 \\
\hline Absence of systemic fluoride & 5 & 12.50 & 3 & 12.50 & 0.6810 \\
\hline Cariogenic Diet & 10 & 25.00 & 11 & 27.50 & 0.0987 \\
\hline Opacity & 26 & 65.00 & 25 & 62.50 & 0.6369 \\
\hline Hypoplasia & 15 & 37.50 & 3 & 7.50 & 0.7008 \\
\hline
\end{tabular}

between low birth weight $(\mathrm{p}<0.0001)$ and prematurity $(\mathrm{p}<0.0020)$ with enamel defects. According to Seow, ${ }^{22}$ very low birth weight was a risk factor for developmental enamel defects in permanent teeth $(\mathrm{p}<0.02)$. Opposite results were found in this study.

As regards the number of caries-free children in the two groups, the results showed that $57.5 \%$ of children in G1 and 35\% of children in G2 had DMFT $=0(\mathrm{p}=0.04)$. It was investigated whether socioeconomic and cultural factors might be influencing these conditions, since approximately $46.5 \%$ of the population in this study was classified as living on the poverty line, based on their per capita income. Regarding education, $79 \%$ of the mothers had completed only elementary education. However, no statistical difference was found between the two groups in terms of the two variables $(\mathrm{p}=0.3576$ and $\mathrm{p}=0.6907)$. Per capita income $(\mathrm{p}=0.39)$ and educational level (0.52) were not risk factors for dental caries. An analysis of deciduous teeth only showed a mean $\mathrm{dmft}$ greater in term infants $(\mathrm{p}=0.0251)$, as shown in Graph 3. Other studies ${ }^{22,23}$ showed similar results, in which premature children showed no more risk of caries than did term infants. The low DMFT values found for the premature group in this study can perhaps be explained by the fact that children had routine follow-up during the first years of life, and were therefore provided with guidance on dietary habits and oral hygiene by the Hospital's (HRAS) neonatology staff.

Concerning permanent teeth, the mean DMFT was 0.18 for both groups (Graph 4). These findings may be due to easier access to available prevention and health enhancing programs geared to school age children. These results coincide with those of Fadavi et al. ${ }^{19}$ who found the same correlation.

Of the 80 children examined, 76 (95\%) brushed their teeth with fluoridated toothpaste more than once a day. Although this variable did not correlate with caries, this habit may have contributed to the low prevalence of caries in the sample since G1 children had DMFT $<1$ and G2 children had DMFT $=2$. Although this study comprised children from a single hospital, our results are in line with the current scenario of decreasing prevalence of caries in Brazil. This may be due to factors like increased population access to fluoridated water programs, addition of fluoride to toothpaste and a practice paradigm shift which prioritizes preventive and health promotion activities. ${ }^{24}$

As regards systemic exposure to fluoride, $87.5 \%$ of children reside in regions where fluoridated water is regularly supplied. The absence of this variable was not a risk factor for caries in this study, probably due to the presence of fluoride in children's toothpaste. Opposite results were found by Cardoso et al. ${ }^{25}$

Only $26 \%$ of the sample followed a cariogenic diet. This might have come as a result of the followup that these infants received from the HRAS medical staff, who provided them with guidance concerning general health and oral care, as well as the wide-ranging oral health promotion and education programs currently implemented in the Brazilian Federal District (Brasília). Provided that diet effects remained under control, type of birth was not a risk factor for the occurrence of caries $(\mathrm{p}=0.1060)$. 
These findings did not coincide with the study by Oliveira et al. ${ }^{14}$ with children from a low socioeconomic and cultural background, who followed - in their majority - a cariogenic diet: a correlation was therefore found between cariogenic diet and caries $(\mathrm{p}<0.05)$.

There was no significant correlation between opacity/hypoplasia and caries $(\mathrm{p}=0.70$ and $\mathrm{p}=0.63$ ) (Table 1). These findings disagree with those of Oliveira et al. ${ }^{14}$ who found a strong correlation between these variables $(p=0.0001)$, in which children with structural enamel defects were 15 times more likely to develop caries in comparison with children free from such defects. Hoffmann et al. ${ }^{26}$ found the prevalence of hypoplasia, demarcated opacity and dental fluorosis in children aged 5 to 12 , in primary and permanent dentition, and also found a correlation between the presence of enamel defects and tooth decay. During primary dentition, there was a positive correlation between dental caries and the three defects investigated in this study $(\mathrm{p}<0.05)$. However, in permanent dentition, only

\section{References}

1. Ferrini FRDO, Marba STM, Gavião MBD. Alterações bucais em crianças prematuras e com baixo peso ao nascer. Rev Paul Pediatr. 2007 Mar;25(1):66-71.

2. Gravina DBL, Cruvinel VRN, Azevedo TDPL, Bezerra ACB, Toledo AO. Prevalence of dental caries in children born prematurely or at full term. Braz Oral Res. 2006 Oct-Dec;20(4):3537.

3. Seow WK, Brown JP, Tudehope DI, O’Callaghan M. Developmental defects in the primary dentition of low birth-weight infants: adverse effects of laryngoscopy and prolonged endotracheal intubation. Pediatr Dent. 1984 Mar;6(1):28-31.

4. FDI Commission on Oral Health - World Dental Press. A review of the developmental defects of enamel index (DDE index). Int Dent J. 1993 Dec;42 (6):411-28.

5. Sawyer DR, Nwoku, AL. Malnutrition and the oral health of children in Ogbomosho, Nigeria. ASDC J Dent Child. 1985 Mar-Apr; 52(2):141-5.

6. Horowitz HS. Research issues in early childhood caries. Community Dent Oral Epidemiol. 1998;26(1 Suppl):67-81.

7. Noren, JG. Intubation and mineralization in the enamel of primary teeth. Acta Odontol Scand. 1993 Oct;51(5):271-5.

8. Li Y, Navia JM, Bian JY. Prevalence and distribution of developmental enamel defects in primary dentition of Chinese hypoplasia and demarcated opacity were associated with caries $(\mathrm{p}<0.004$ and $\mathrm{p}<0.008$, respectively). Milgrom et al. ${ }^{27}$ evaluated the relationship between dental caries and factors such as hygiene, bacteria, diet and hypoplasia. They concluded that hypoplasia is an important etiological factor in the population studied. The study by Ribeiro et al. ${ }^{16}$ also differs from the present study, as those authors concluded that the presence of enamel defects was the only statistically significant factor associated with the development of early childhood caries. Diet, hygiene and use of fluoride were found to have no significant correlation with this condition.

\section{Conclusions}

In this study, the mean DMFT of the premature and term groups was not statistically significant, and was not correlated with enamel defects. Income, schooling, hygiene, fluoride exposure, diet, opacity, hypoplasia and birth weight also did not correlate with the onset of dental caries.

children 3-5 years old. Community Dent Oral Epidemiol. 1995 Apr;23(2):72-9.

9. Dini El, Holt RD, Edi R. Caries and its association with infant feeding and oral health-related behaviours in 3-4 year-old Brazilian children. Community Dent Oral Epidemiol. 2000 Aug;28(4):241-8.

10. Rosenblatt A, Zarzar PMPA. The prevalence of early childhood caries in 12- to 36-month-old children in Recife, Brazil. ASDC J Dent Child. 2002 Sep-Dec;69(3):319-24.

11. Davenport ES, Litenas C, Barbayiannis P, Williams CES. The effects of diet, breast-feeding and weaning on caries risk for pre-term and low birth weight children. Int J Paediatr Dent. 2004 Jul;14(4):251-9.

12. Instituto Brasileiro de Geografia e Estatística. Síntese de Indicadores sociais 2006: estudos e pesquisas. Informação demográfica e sócio-econômica. 2006 [citado 14 mai. 2008]. Disponível em: http://www.ibge.gov.br/home/estatistica/populacao/trabalhoerendimento/pnad2006/default.shtm.

13. Massoni ACLT, Oliveira AFB, Chaves AMBC, Sampaio FC, Rosenblatt A. Fatores sócio-econômicos relacionados ao risco nutricional e sua associação com a freqüência de defeitos do esmalte em crianças da cidade de João Pessoa, Paraíba, Brasil. Cad Saude Publica. 2007 Dec;23(12):2928-37. 
14. Oliveira AFB, Chaves AMB, Rosenblatt A. The influence of enamel defects on the development of early childhood caries in a population with low socioeconomic status: a longitudinal study. Caries Res. 2006;40(4):296-302.

15. Azevedo TDPL, Bezerra ACB, Toledo OA. Feeding habits and severe early childhood caries in Brazilian preschool children. Pediatr Dent. 2005 Jan-Feb;27(1):28-33.

16. Ribeiro AG, Oliveira AF, Rosenblatt A. Cárie precoce na infância: prevalência e fatores de risco em pré-escolares, aos 48 meses, na cidade de João Pessoa, Paraíba Brasil. Cad Saude Publica. 2005 Nov-Dec;21(6):1695-700.

17. Lunardelli SE, Peres MA. Prevalence and distribution of developmental enamel defects in the primary dentition of preschool children. Braz Oral Res. 2005 Apr-Jun;19(2):144-9.

18. Pinto VG. Saúde Bucal Coletiva. $5^{\text {a }}$ ed. São Paulo: Santos; 2008. $635 \mathrm{p}$.

19. Fadavi S, Punwani I, Vidyasagar D. Prevalence of dental caries in prematurely-born children. J Clin Pediatr Dent. 1993;17(3):163-5.

20. Maatouk F, Belgacem B, Belgacem R, Ghedira H, Jemmali B. Prevalence of dental caries in children with low birth weight. East Mediterr Health J. 1996;2(2):311-4.

21. Lai PY, Seow WK, Tudehope DI. Enamel hypoplasia and dental caries in very-low birthweight children: a case-controlled, longitudinal study. Pediatr Dent. 1997 Jan-Feb;19(1):42-9.
22. Seow WK. A study of the development of the permanent dentition in very low birth weight children. Pediatr Dent. 1996 Sep-Oct;18(5):379-84.

23. Fearne JM, Bryan EM, Elliman AM, Brook AH, Williams DM. Enamel defects in the primary dentition of children born weighing less than 2000g. Br Dent J. 1990 Jun;168(11):4337.

24. Kriger L. Aboprev: Promoção de saúde bucal: paradigma, ciência, humanização. $3^{\mathrm{a}}$ ed. Rio de Janeiro: Artes Médicas; 2003. $504 \mathrm{p}$.

25. Cardoso L, Rösing C, Kramer P, Costa CC, Costa Filho LC. Polarização da cárie em município sem água fluoretada. Cad. Saude Publica. 2003 Jan-Fev;19(1):237-43.

26. Hoffmann RHS, Sousa MLR, Cypriano S. Prevalência de defeitos de esmalte e sua relação com cárie dentária nas dentições decídua e permanente, Indaiatuba, São Paulo, Brasil. Cad Saude Publica. 2007 Feb;23(2):435-44.

27. Milgrom P, Riedy CA, Weinstein P, Tanner ACR, Manibusan L, Bruss J. Dental caries and its relationship to bacterial infection hypoplasia, diet and oral hygiene in 6 to 36 month-old children. Community Dent Oral Epidemiol. 2000 Aug;28(4):295-306. 